\title{
Manifestations of rheumatoid arthritis: epidural pannus and atlantoaxial subluxation resulting in basilar invagination.
}

Adam L Schreiber, DO, MA

Thomas Jefferson University

Follow this and additional works at: https://jdc.jefferson.edu/rmfp

Part of the Neurology Commons, and the Rehabilitation and Therapy Commons Let us know how access to this document benefits you

\section{Recommended Citation}

Schreiber, DO, MA, Adam L, "Manifestations of rheumatoid arthritis: epidural pannus and atlantoaxial subluxation resulting in basilar invagination." (2012). Department of Rehabilitation Medicine Faculty Papers. Paper 8.

https://jdc.jefferson.edu/rmfp/8

This Article is brought to you for free and open access by the Jefferson Digital Commons. The Jefferson Digital Commons is a service of Thomas Jefferson University's Center for Teaching and Learning (CTL). The Commons is a showcase for Jefferson books and journals, peer-reviewed scholarly publications, unique historical collections from the University archives, and teaching tools. The Jefferson Digital Commons allows researchers and interested readers anywhere in the world to learn about and keep up to date with Jefferson scholarship. This article has been accepted for inclusion in Department of Rehabilitation Medicine Faculty Papers by an authorized administrator of the Jefferson Digital Commons. For more information, please contact: JeffersonDigitalCommons@jefferson.edu. 


\title{
As submitted to:
}

\author{
PM\&R
}

\section{And later published as:}

\section{Images \\ Manifestations of Rheumatoid Arthritis: Epidural Pannus and Atlantoaxial Subluxation Resulting in Basilar Invagination}

\author{
Volume 4, Issue 1, January 2012, Pages 78-80 \\ DOI: 10.1016/j.pmrj.2011.08.670
}

Adam L. Schreiber, DO, MA

Atlantoaxial instability results from cartilaginous destruction, periarticular erosions, and ligament and tendon attenuation. Instability affects 19\%-70\% of patients, and basilar invagination from vertical odontoid subluxation through the foramen magnum occurs in $38 \%$ of patients. This phenomenon occurs twice as often in women than men, whose age at diagnosis typically ranges from 30-50 years. Along with bony compression, the pannus further decreases the space available for the cord by 3 mmor more in approximately $66 \%$ of patients (Figures 1-7). The earliest and most common symptom of cervical subluxation is pain radiating up into the occiput with associated headaches. Episodes of medullary dysfunction that represent severe but less common patterns of progressive myelopathic symptoms provide an even more grim prognosis. When cervical myelopathy is established, 50\% of these patients die within 1 year.

The incidence of sudden death from the combination of basilar impression and atlantoaxial instability is $10 \%$. Preoperative neurological deficits provide a guarded prognosis, and basilar impression is associated with poorer recovery of function [1,2]. McRorie et al [3] researched surgical outcomes and found that no clear factors emerged to predict the greatest risk of operative mortality. Neurological compromise did not correlate with immediate perioperative death, and early surgery to correct symptomatic atlantoaxial subluxation may prevent the progression of instability.

A.L.S. Department of Rehabilitation Medicine, Jefferson Medical College of Thomas Jefferson University, Philadelphia, PA.

Address correspondence to: A.L.S.,

Jefferson Medical College of Thomas Jefferson University, $25 \mathrm{~S} 9^{\text {th }}$ Street

Philadelphia, PA 19107

e-mail:schreiberdo@yahoo.com

Disclosure: nothing to disclose 
Presented in part at the AAPMR 71st Annual Assembly Meeting, Seattle, WA, November 4-7, 2010. Submitted for publication August 17, 2011; accepted August 31, 2011.

PM\&R Vol. 4, 78-80, January 2012 




Figure 1. A cervical spine sagittal computed tomography scan reveals pannus formation (right arrows) and superior odontoid migration causing basilar invagination (left arrow). (Scan was performed with a Philips Brilliance 64 computed tomography scanner with 0.9-mm slices). 


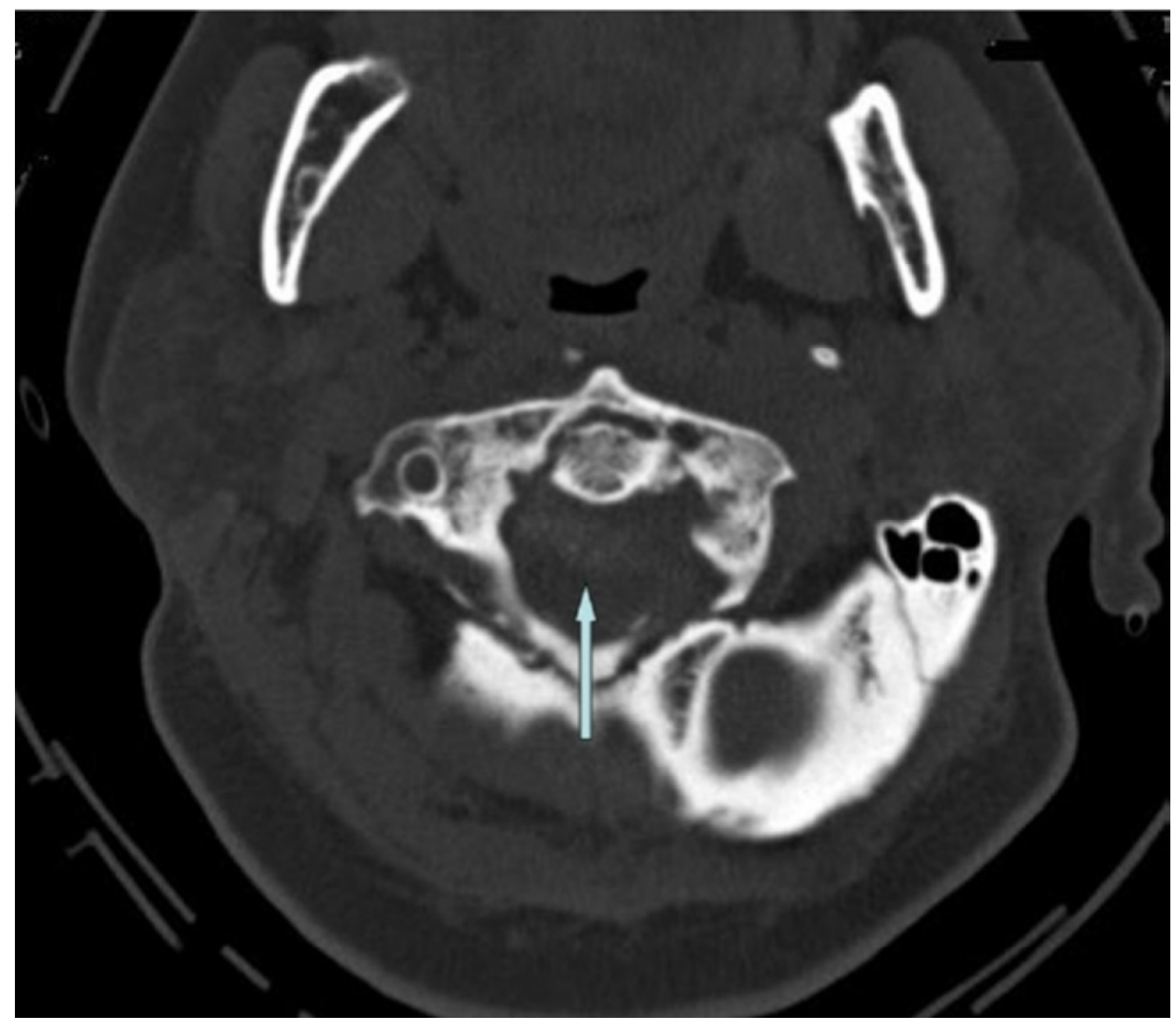

Figure 2. A cervical spine axial computed tomography scan at the $\mathrm{C} 2$ level reveals pannus formation within the central canal causing canal stenosis (arrow). (Scan was performed with a Philips Brilliance 64 computed tomography scanner with 0.9-mm slices.) 


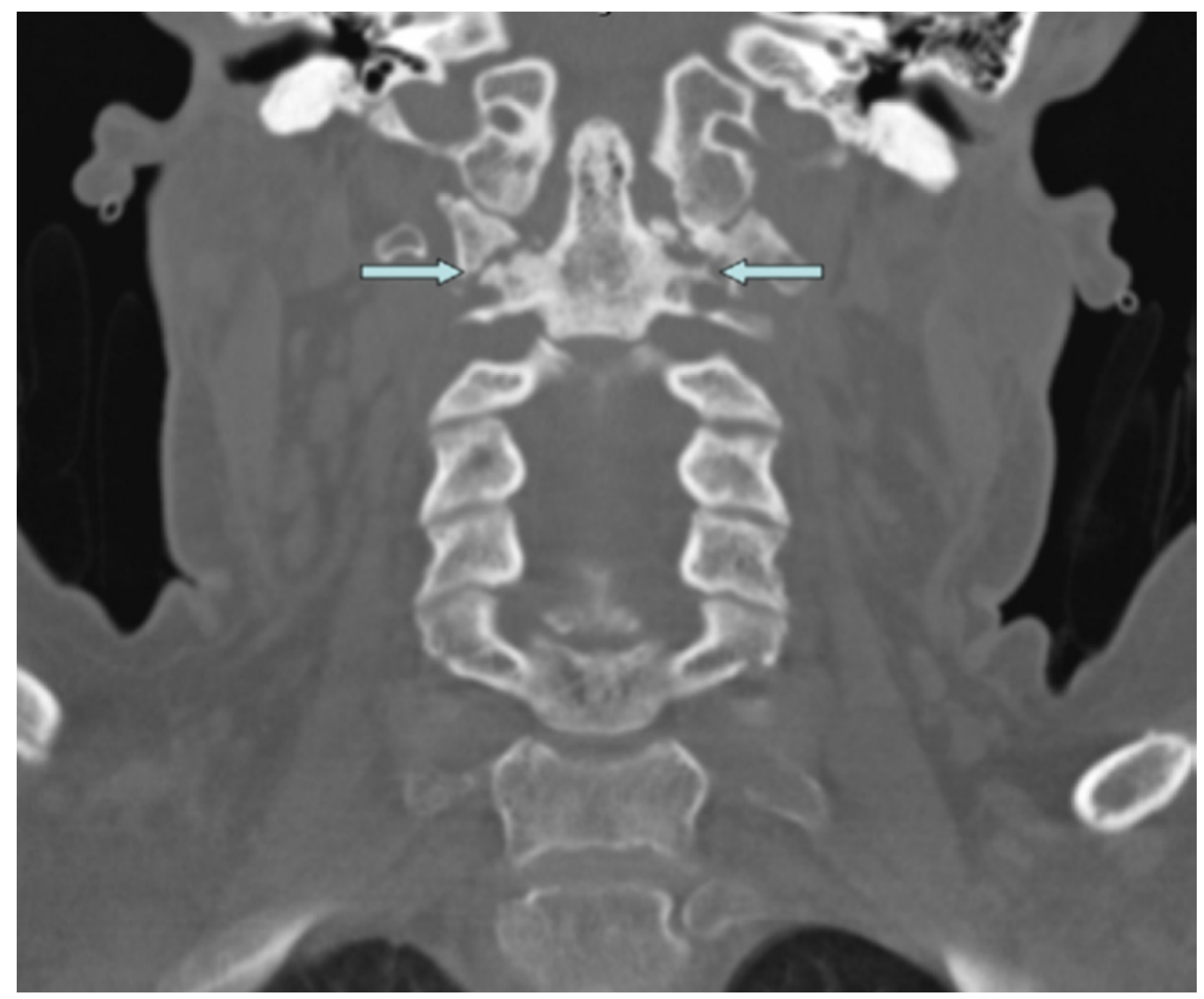

Figure 3. A cervical spine coronal computed tomography scan reveals superior odontoid migration with C1-C2 erosions (left and right arrows). (Scan was performed with a Philips Brilliance 64 computed tomography scanner with 0.9-mm slices.) 


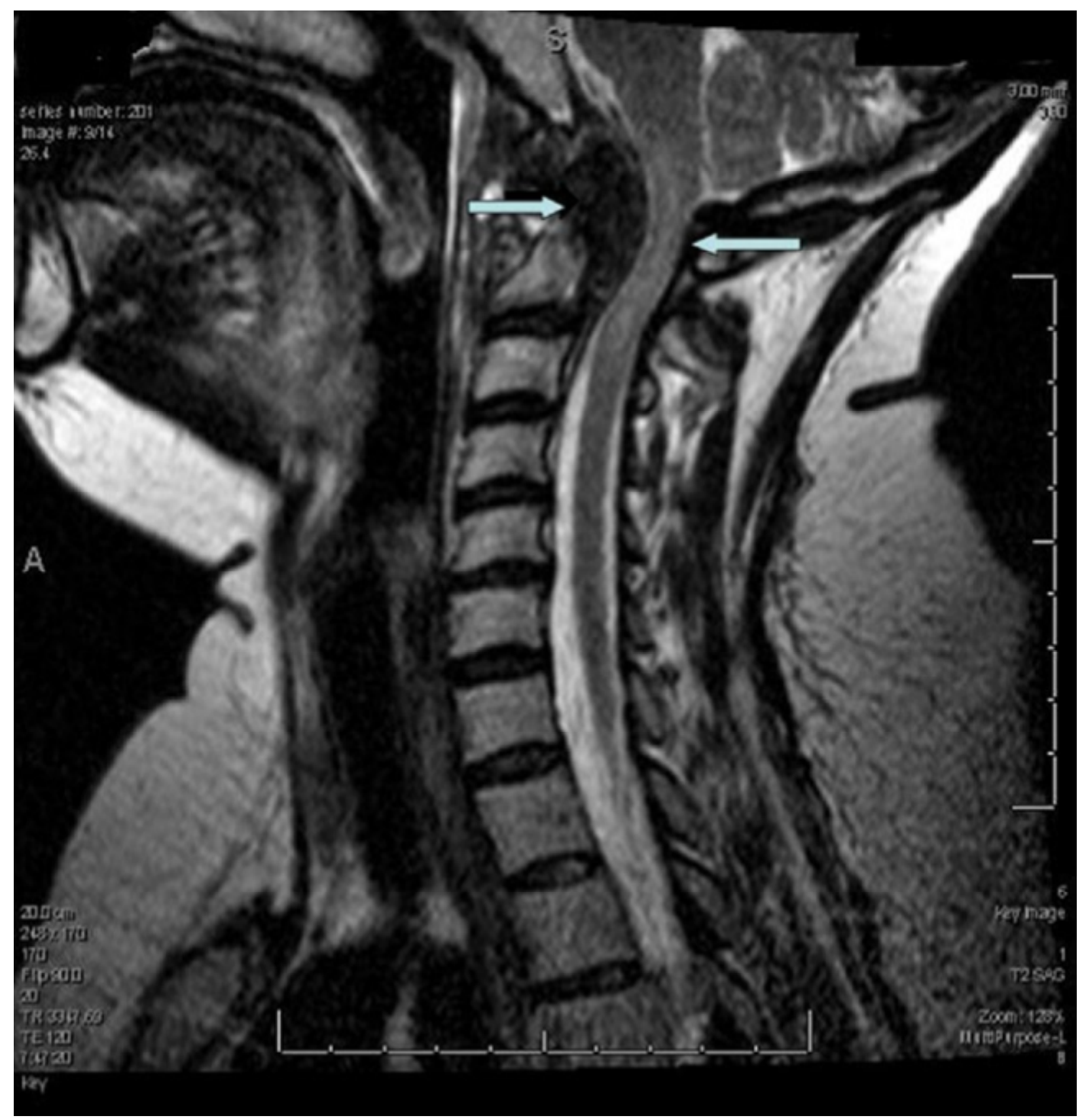

Figure 4. A cervical spine sagittal T2-weighted magnetic resonance imaging scan reveals pannus formation (left arrow) causing spinal canal stenosis and T2 hyperintensity within the spinal cord (right arrow). (Scan was performed with a Philips 1 Tesla Panorama magnetic resonance imaging unit with 3-mm/ 1-mm skip.) 


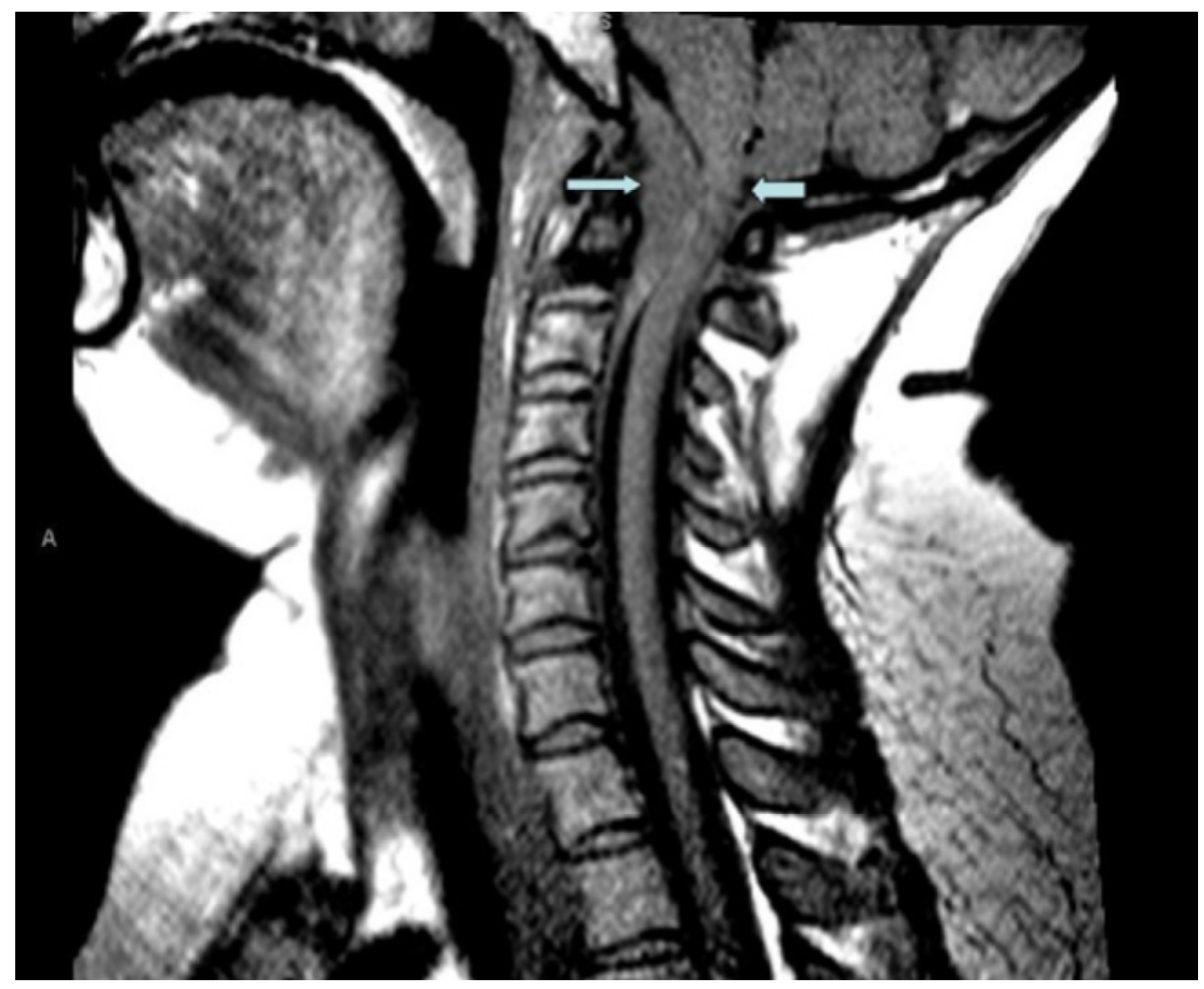

Figure 5. A cervical spine sagittal $\mathrm{Tl}$-weighted magnetic resonance imaging scan reveals pannus (left arrow) causing canal stenosis and spinal cord compression (right arrow). (Scan was performed with a Philips 1 Tesla Panorama magnetic resonance imaging unit with 3-mm/1-mm skip.) 




Figure 6. A lateral cervical radiograph shows odontoid process within the foramen magnum after cranial settling causing basilar invagination (right arrow). 


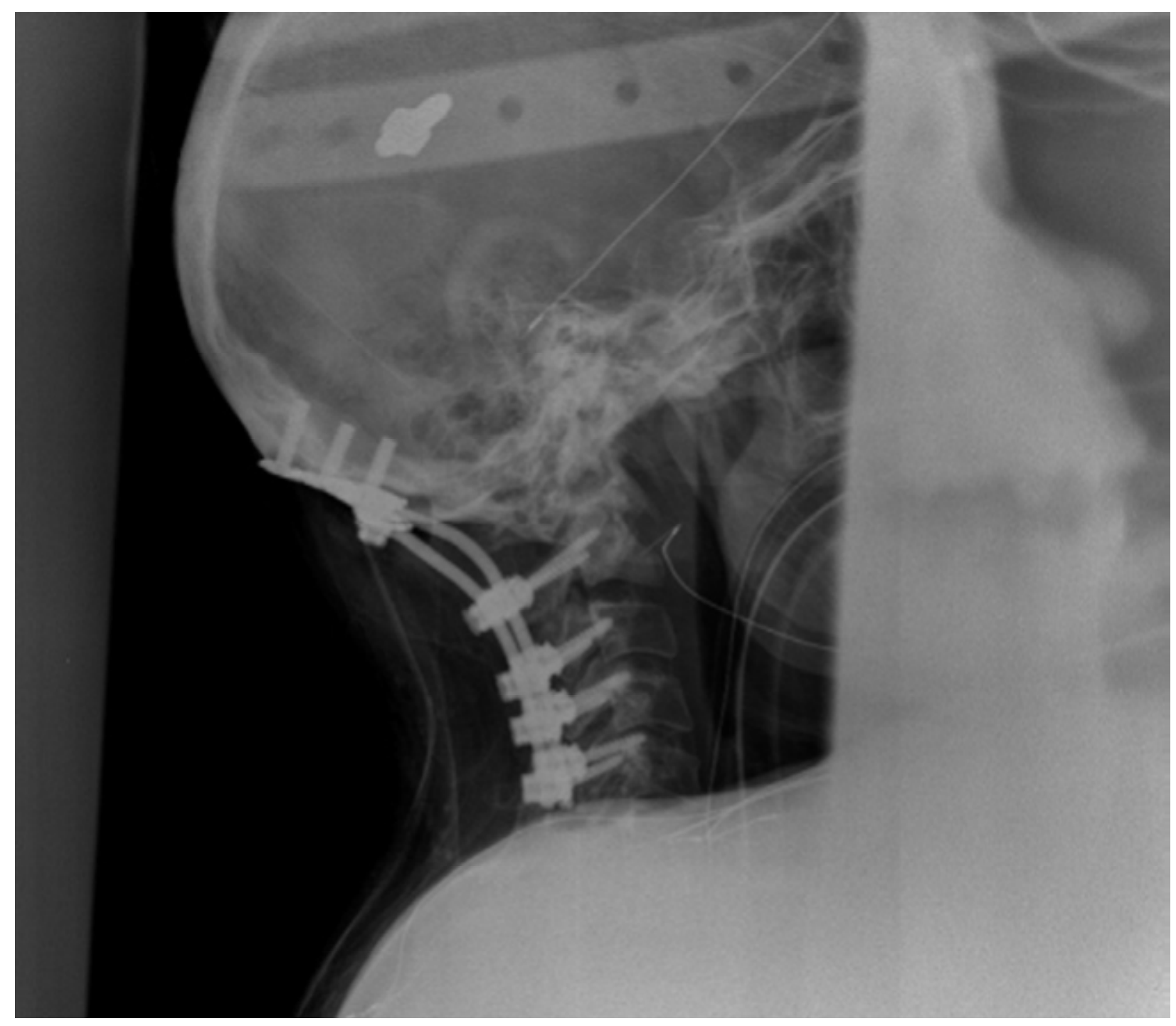

Figure 7. A lateral cervical radiograph shows posterior fixation from the occiput to C5. 


\section{REFERENCES}

1. Harris ED, Firestein GS. Course and complications of established rheumatoid arthritis. In: Firestein GS, Budd RC, HarrisEDJr, et al. Kelley's Textbook

of Rheumatology, 8th ed. St. Louis, MO: W. B. Saunders; 2008.

2. Beaty JH, Canale ST. Rheumatoid arthritis of the spine. In: Beaty JH,

Canale ST, eds. Campbell's Operative Orthopaedics, 11th ed. St. Louis,

MO: Mosby; 2007.

3. McRorie ER, McLoughlin P, Russell T, Beggs I, Nuki G, Hurs NP.

Cervical spine surgery in patients with rheumatoid arthritis: An appraisal. Ann Rheum Dis 1996:55:99-104. 